\title{
Global Ocean Warming: Detection By Long-Path Acoustic Travel Times
}

\author{
By Walter Munk
}

\section{... Heard Island}

could be heard on both

sides of North America.
$\mathrm{M}$

Y INTEREST in an acoustic measure of global ocean warming came up suddenly in April 1988. I had given a lecture invited by the Office of Naval Research (ONR) on the subject of a 1960 experiment (Shockley et al. . 1982) in which 300 lbs. of dynamite were detonated in the sound channel off Perth, Australia. The explosion was clearly recorded by Bermuda hydrophones halfway around the earth. The authors had interpreted the result as a transmission along the unimpeded oceanic great-circle route between Perth and Bermuda. Munk. O'Reilly and Reid (1988) asked the question whether the neglect of lateral refraction and of the earth"s ellipticity was justified. Accordingly, they constructed a set of refracted geodesics radiating out of the shot site. Surprisingly, the north-south temperature gradient associated with the Antarctic Circumpolar Current deflects the rays to the left south so severely that they never make it to Bermuda: the island lics in the geometric shadow. It is not clear what scattering process was responsible for putting enough energy into the shadow zone for the explosions to be heard at Bermuda.

At the end of the lalk, the question was raised of how one would go about doing such an experiment today" The obvious answer is that one would look for a source site farther south. with unimpeded access to Bermuda. But why do such an experiment in the first place? The question immediately suggested that this might be a way of measuring global ocean warming. The speed of sound increases with temperature, and accordingly, the travel time between fixed points would diminish as the ocean warmed.

Andrew Forbes of the Commonwealth Scientific and Industrial Research Organization (CSIRO) Marine Laboratory in Hobart. Tasmania was visiting Scripps Institution, and we set about trying to answer four questions (Munk and Forbes, 1989):

- What is a good site? After many tries we chosc Heard Island (Australia) in the Indian Ocean. Not only is there an unimpeded refracted geodesic to Bermuda, but there appears to be a path eastward through a Polynesian window to San Francisco and

Walter Munk. University of California. San Diego. Institute of Geophysics and Planetary Physics, A-1025. La Jolla, CA 921193. a Tasman Sea window to Coos Bay, Oregon. Thus, a suitable source at Heard lsland could be heard on both sides of North America. The site has access to all the major ocean basins, the North and South Atlantic, the North and South Pacific. the Indian Ocean and its adjoining sector of the Antarctic Ocean. It is the most ambitious site, deliberately chosen to bracket the problem of what can be done with global ocean temperature soundings.

- How big is the signal? We estimate a greenhouseinduced decrease in travel time of 0.2 to 0.5 seconds per year. In our tomographic work (see Munk and Worcester. 1988). We routinely measure to a precision of $1 \mathrm{~ms}$ at $1000 \mathrm{~km}$ ranges.

- How big is the geophysical noise? This is a more difficult question. We estimate $0.5 \mathrm{~s}$ from global mesoscale activity, and possibly larger fluctuations from basin scale variability.

- Does this require explosive sources (as in 1960)? No, we belicve that existing, low-frequency, electrically-driven sources would do. We have formed a small informal group (Ted Birdsall. Mel Briscoe, Andrew Forbes, Kurt Metzger, Walter Munk and Robert Spindel) to plan for a feasibility test carly in 1991. This involves transmission from a ship-suspended source for one week, to be monitored off Bermuda, the American West Coast. New Zealand. Tasmania and other sites. If this is successful. we would attempt a permanent off-shore installation connected by cable to Heard Island and received at two to three dozen sites in all five ocean basins. We estimate that ten years are required to measure the warming trend.

How would the time series of acoustic travel time be used"? Initially, they provide a check on the validity of the numerical models. Each source-to-receiver path is essentially a long line-integral of temperature $\theta$ within the ocean volume. $I=\int \theta(x, y . x)$ ds. The acoustic time series yields $I(t)$. If model and measurements agree, then the model prediction gains respectability as a basis for planning. If they disagree, then presumably one can get to the bottom of where the discrepancy arises and improve the model.

The proposed experiment then serves as a classical assimilation experiment. It is not an application of ocean acoustic tomography, which consists of a 


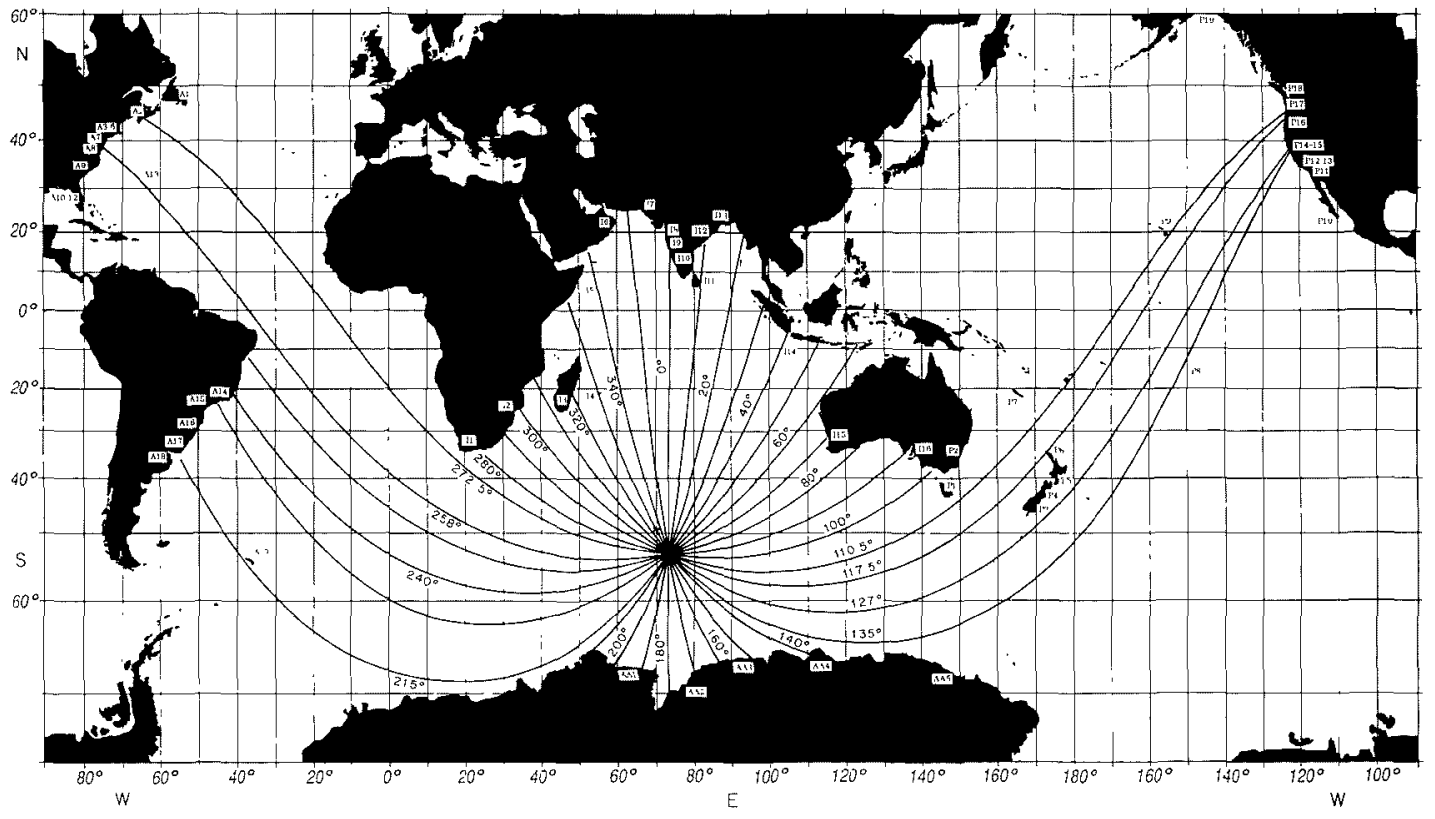

Fig. I: Refracted rass (allowing for ellipticity) out of Heard sland. with indicated lanthe angles. There are whimpeded paths westward to Bermuda. and eastward to nerthern California. and to many other locations. White boves indicate locations where oceanostaphic research stations are located. From Munk and Forbes, 1989. Reprinted with permission from Journal of Physical Oceanography, American Meteorological Society.

sufficient network of ray paths so that travel times can be inverted to yield $\theta(x, y, z)$ quite independent of any theory or modeling effort. Could one conceive an augmentation of the Heard Island experiment which would in fact be invertible to yield temperature change with gyre or basin resolution? Andrew Forbes has constructed diagrams of refracted geodesics emanating from the South Georgia Islands and St. Helena in the South Atlantic, Macquarie and Pitcairn Islands in the South Pacific (in addition to Heard Island). The diversity of ray paths from the five locations is remarkable, and we are studying the problem as to whether their combined use lends itself to a global tomography. I think that a "southern strategy" of sources in the southern oceans is called for, given the distribution of oceans and continents.

\section{References}

Munk, Walter and Andrew Forbe, 1989: Global Occan Warmmng: An Acoustic Measure? I Phy. Occumegr.. I9. (in press).

Munk. W.H., W.C. O'Reilly and J.L. Reid, I9s8: AustraliatBermuda Sound Transmission Experiment (1960) Revisited. I. Phy Occanogr., IS4/2), 1876-1898.

Munk. Walter and Peter Worcester. 1988: Ocean Acoustic Tomography. Occunosr. Mag. ////) 8-10.

Shochley, R.C..J. Northrop. P.G. Hansen and C. Hartdegen. 1982: SOFAR (Sound Fixing and Ranging) propagation paths from Australia to Bermuda: Comparison of Signal Speed Algorthms and Experiment. J. Acoust. Sin Amer. $7 / .51-$ 60. J 